\title{
Pheochromocytoma and paraganglioma: current functional and future molecular imaging
}

\author{
Elise M. Blanchet ${ }^{1,2}$, Victoria Martucci ${ }^{1,2}$ and Karel Pacak ${ }^{1,2 *}$ \\ ${ }^{1}$ Department of Nuclear Medicine, Centre Hospitalo-Universitaire d'Angers, Angers, France \\ 2 Program in Reproductive and Adult Endocrinology, Eunice Kennedy Shriver National Institute of Child Health and Human Development, National Institutes of \\ Health, Bethesda, MD, USA
}

\section{Edited by:}

Georgios Limouris, Athens University Medical Faculty, Greece

\section{Reviewed by:}

Mustafa Erkan Altinyay, NGHA-King

Fahad Hospital, Saudi Arabia

Chaitanya Divgi, Columbia University, USA

\section{${ }^{*}$ Correspondence:}

Karel Pacak, Program in Reproductive and Adult Endocrinology, Eunice

Kennedy Shriver National Institute of Child Health and Human

Development, National Institutes of Health, Building 10, CRC, 1-East,

Room 1-3140, 10 Center Drive,

MSC-1109, Bethesda, MD

20892-1109, USA.

e-mail: karel@mail.nih.gov
Paragangliomas are neural crest-derived tumors, arising either from chromaffin sympathetic tissue (in adrenal, abdominal, intra-pelvic, or thoracic paraganglia) or from parasympathetic tissue (in head and neck paraganglia). They have a specific cellular metabolism, with the ability to synthesize, store, and secrete catecholamines (although most head and neck paragangliomas do not secrete any catecholamines). This disease is rare and also very heterogeneous, with various presentations (e.g., in regards to localization, multifocality, potential to metastasize, biochemical phenotype, and genetic background). With growing knowledge, notably about the pathophysiology and genetic background, guidelines are evolving rapidly. In this context, functional imaging is a challenge for the management of paragangliomas. Nuclear imaging has been used for exploring paragangliomas for the last three decades, with MIBG historically as the first-line exam. Tracers used in paragangliomas can be grouped in three different categories. Agents that specifically target catecholamine synthesis, storage, and secretion pathways include: 123 and 131I-metaiodobenzylguanidine (123/1311MIBG), 18F-fluorodopamine (18F-FDA), and 18F-fluorodihydroxyphenylalanine (18F-FDOPA). Agents that bind somatostatin receptors include $111 \mathrm{ln}$-pentetreotide and 68Ga-labeled somatostatin analog peptides (68Ga-DOTA-TOC, 68Ga-DOTA-NOC, 68Ga-DOTA-TATE). The non-specific agent most commonly used in paragangliomas is $18 \mathrm{~F}$-fluorodeoxyglucose (18FFDG). This review will first describe conventional scintigraphic exams that are used for imaging paragangliomas. In the second part we will emphasize the interest in new PET approaches (specific and non-specific), considering the growing knowledge about genetic background and pathophysiology, with the aim of understanding how tumors behave, and optimally adjusting imaging technique for each tumor type.

Keywords: pheochromocytoma and paraganglioma, radionuclide imaging, positron emission tomography, genetic mutation, 18F-fluorodeoxyglucose, 18F-fluorodopamine, 18F-fluorodihydroxyphenylalanine

\section{PHEOCHROMOCYTOMA AND PARAGANGLIOMA}

Paragangliomas are autonomic nervous system tumors, derived from the neural crest. They can be divided in two groups: those that arise from sympathetic-associated chromaffin tissue in adrenal and extra-adrenal abdominal, intra-pelvic, or thoracic locations (when such tumors arise from the adrenal medulla they are called pheochromocytomas), and those that arise from head and neck parasympathetic-associated tissue (most commonly along the cranial and vagus nerves).These two entities have distinctive biochemical and clinical properties. Parasympathetic head and neck paragangliomas rarely produce a significant amount of catecholamines, whereas almost all sympathetic paragangliomas produce and secrete catecholamines or their metabolites (Eisenhofer, 2001). This hormonal excess can induce severe cardiovascular and cerebrovascular complications. For head and neck paragangliomas which do not secrete catecholamines, complications can result from mass effect. Another important factor in determining the prognosis is the malignancy status.

There are currently no validated histological criteria for malignancy (Tischler, 2008). The diagnosis of malignant paraganglioma, often established late, is based only on the occurrence of the first metastasis (defined by presence of tumoral cells at non-neural-crest-derived sites; DeLellis, 2004).Two risk factors have classically been associated with poor prognosis: a tumor size exceeding $5 \mathrm{~cm}$ and an extra-adrenal localization. It has been previously estimated that $10 \%$ of paragangliomas are malignant, but this estimation is no longer valid. In fact, it has been demonstrated that the prevalence of malignant lesions depends directly on the underlying mutation.

Paragangliomas occur either sporadically or as part of a hereditary syndrome. According to the latest studies, $30 \%$ or more of paragangliomas may be due to an inherited origin (GimenezRoqueplo et al., 2008). Patients with an inherited predisposition often develop multiple, bilateral, and early onset paragangliomas (as a result of germline mutations in the predisposing genes; Amar et al., 2005). The following hereditary syndromes have been identified so far: multiple endocrine neoplasia type 2 (MEN2), neurofibromatosis type 1 (NF1), von Hippel-Lindau disease (VHL), and hereditary paraganglioma. These syndromes are caused by mutations in the RET, VHL, NF1, and succinate dehydrogenase 
(SDH) -B, -C, and -D genes, respectively (Bryant et al., 2003). Moreover, newly discovered genes have recently also been linked to hereditary paragangliomas (SDHAF2, also called SDH5, SDHA, TMEM127, and MAX; Hao et al., 2009; Burnichon et al., 2010; Qin et al., 2010; Comino-Méndez et al., 2011).

SDHB gene mutations are known to be associated with extra-adrenal localization, overproduction of norepinephrine and dopamine, and a high risk of malignancy with a poor prognosis (Gimenez-Roqueplo et al., 2003; Neumann et al., 2004; Amar et al., 2007; Timmers et al., 2007a). In contrast to the high malignant potential of tumors related to SDHB germline mutations, patients with NF1,RET, VHL, and SDHD mutations rarely develop metastases (Amar et al., 2005; Gimenez-Roqueplo et al., 2006). All these underlying mutations can lead to various tumor locations (with the possibility of multifocal disease), biochemical phenotypes, and malignant potentials: thus paragangliomas are exemplary for functional imaging.

Moreover, some studies have recently described molecular phenomena and specific pathways that occur in each specific pattern of paraganglioma. In particular, transcriptional profiling studies revealed pseudo-hypoxic signatures in SDHx/VHL tumors, which result in the stabilization of hypoxic-inducible factor (HIF)-1alpha and the overexpression of its target genes (genes regulating angiogenesis, proliferation, apoptosis, invasion, and energy metabolism; Favier and Gimenez-Roqueplo, 2010).

In this context the goal is then to perform imaging studies adapted to each individual patient, according to his syndrome and genetic background. This would allow for earlier detection of lesions, better understanding of how tumors behave, and development of new therapeutic approaches.

\section{CURRENT FUNCTIONAL IMAGING}

Nuclear imaging has been used for exploring paragangliomas for the last three decades. It has rapidly proved its complementarity with anatomical imaging, thanks to the better specificity and the possibility of performing full-body imaging, which is useful in the presence of various tumor locations and with the possibility of multifocality or metastases.

\section{I131/123 MIBG SCINTIGRAPHY}

131/123I-MIBG scintigraphy has been, for a long time, the main functional imaging modality for the localization and diagnosis of paragangliomas (Sisson et al., 1981) and is still the most commonly used tracer for this purpose. An analog of norepinephrine, MIBG enters cells through the cell membrane norepinephrine transporter (NET) and is then transported and stored in neurosecretory granules via the vesicular monoamine transporter (VMAT; Eisenhofer, 2001). There are two types of VMAT (VMAT-1 and -2; Fottner et al., 2010).

Although 131I-labeled MIBG was initially used for scintigraphy, the superiority of 123I-labeledMIBG has been demonstrated (Lynn et al., 1985; Shulkin et al., 1986), due to its higher sensitivity, lower radiation exposure, and improved imaging quality with the possibility of SPECT imaging.

123I-MIBG performance in primary sympathetic paragangliomas has been proven in many studies (Timmers et al., 2009a; Wiseman et al., 2009). However, numerous studies emphasize that
123I-MIBG imaging is less effective for metastatic disease. To explain this on a molecular level, it has been suggested that paragangliomas could undergo dedifferentiation, leading to a loss of NET or VMAT, which could then lead to false negatives (Eisenhofer, 2001). Timmers, in a prospective study of 26 patients, found 123I-MIBG sensitivities of $77 \%$ for non-metastatic paragangliomas and $57 \%$ for metastatic paragangliomas (Timmers et al., 2009a). Consequently, it has been suggested that in the case of metastatic paraganglioma, the use of 123I-MIBG scintigraphy should be limited to the determination of patients' eligibility for 131I-MIBG treatment.

In contrast to the excellence of 123I-MIBG for the detection of primary sympathetic paragangliomas, its sensitivity is low in head and neck paragangliomas (King et al., 2011). Fottner et al. (2010) suggests that this could result from the under-expression of VMAT-1 in head and neck paragangliomas.

Besides the limitations related to the type of paraganglioma, other drawbacks must be mentioned. First, the timing of the exam is not optimal, with a need for a minimum of $24 \mathrm{~h}$ between injection and imaging. Also, physiologic uptake of 131/123I-MIBG in the adrenal glands could be responsible for false positives. To improve the accuracy of 131/123I-MIBG scintigraphy in the adrenals, a scoring system has been proposed, comparing uptake of the adrenals to that of the liver (Cecchin et al., 2006). An additional limitation is that drugs that act on the adrenergic system could interact with MIBG (Solanki et al., 1992).

To summarize, 123I-MIBG has high sensitivity for primary sympathetic paragangliomas, but poor sensitivity for metastases; therefore it is only useful in metastatic patients to evaluate whether they qualify for 131I-MIBG treatment.

\section{In-PENTETREOTIDE}

In addition to 131/123I-MIBG, 111In-Pentetreotide (Octreoscan) scintigraphy, proven to be valuable in imaging neuroendocrine tumors (Lamberts et al., 1993), has also been studied in paragangliomas. 111In-Pentetreotide is a ligand of somatostatin receptors (SSR), which are known to be expressed in paragangliomas (Reubi et al., 1992). Various subtypes of SSRs have been identified, numbered from 1 to 5 ; 111In-Pentetreotide has the highest affinity to subtypes 2 and 5 (de Herder and Lamberts, 2002).

As shown by Ilias et al. (2008), scintigraphy with 111InPentetreotide has a low sensitivity for primary sympathetic paragangliomas. However, it can be very useful for detecting metastatic disease (van der Harst et al., 2001; Ilias et al., 2008) and parasympathetic head and neck paragangliomas (Koopmans et al., 2008). It has been suggested that these differences in sensitivities are related to the expression of specific subtypes of SSRs.

Based on these studies, 111In-Pentetreotide is not recommended as a first-line imaging tool in paragangliomas. It can be useful if PET is not available, for head and neck paragangliomas, or in conjunction with 123I-MIBG in cases of proven or suspected metastases (van der Harst et al., 2001). Novel SSR-based PET scanning has been introduced recently with promising results, and will be discussed in the next section.

To summarize, conventional imaging, despite its improvement as a result of the development of SPECT and hybrid imaging with CT, still lacks sensitivity in comparison with PET. Moreover it 
requires very long acquisition times. However, 123I-MIBG does have a high sensitivity and must be considered as a useful tracer in cases of adrenal non-metastatic paragangliomas. In other cases, 123I-MIBG should be done only when checking if 131I-MIBG therapy is feasible. 111In-Pentetreotide can be useful if PET is not available (for head and neck paragangliomas, or in conjunction with 123I-MIBG in cases of proven or suspected metastases). This emphasizes the crucial importance of PET in the imaging of paragangliomas.

\section{FUTURE EMERGING MOLECULAR IMAGING}

Following the need for personalized imaging adapted to each pattern of paragangliomas, several PET agents were developed and evaluated, some with very promising results. The aim of this imaging approach is not only to establish the precise localization and diagnosis of paraganglioma, but also to understand how the tumor behaves (aggressiveness, molecular pathways, response to treatment). The advantages of PET imaging compared to monophotonic-emission scintigraphy include rapid imaging, high spatial and temporal resolution, the relatively short half-life of PET radionuclides (compared to those used in conventional imaging), allowing higher dose injection with an acceptable dosimetry, and the ability to acquire quantitative information, which may be useful for follow-up of the disease. PET imaging offers the possibility of $3 \mathrm{D}$ and hybrid imaging with a better resolution and shorter acquisition time than with SPECT imaging. The characteristics of radiotracers used in paragangliomas are summarized in Table $\mathbf{1 .}$

Several PET agents are now available for imaging paragangliomas. Agents labeled with 18 -fluorine (18F) are the most popular, since $18 \mathrm{~F}$ is stable and has an easy labeling process, as well as a suitable half-life. Mechanisms of uptake of several PET tracers are summarized in a schematic display in Figure $\mathbf{1}$.

\section{F-FDA}

Like 123I-MIBG, 18F-FDA uses an agent that specifically targets catecholamine synthesis, storage, and secretion pathways. It is actively transported into neurosecretory granules of catecholamine-producing cells via VMAT, after uptake by NET (Eisenhofer, 2001).

Developed at the National Institutes of Health, 18F-FDA was initially used for sympathetic nervous system functional imaging, and then evaluated as a new imaging tool for paragangliomas

Table 1 | Radiotracers used in functional imaging of paragangliomas.

\begin{tabular}{llll}
\hline $\begin{array}{l}\text { Mechanism of } \\
\text { uptake }\end{array}$ & Radiotracer & $\begin{array}{l}\text { Imaging } \\
\text { technique }\end{array}$ & $\mathbf{T 1 / 2}$ \\
\hline Catecholamine & 131I-MIBG & Planar, SPECT & 8 days \\
metabolism & 123I-MIBG & Planar, SPECT & $13 \mathrm{~h}$ \\
& 124I-MIBG & PET & 4 days \\
& 18F-FDOPA & PET & $110 \mathrm{~min}$ \\
& 18F-FDA & PET & $110 \mathrm{~min}$ \\
11C-epinephrine & PET & $20 \mathrm{~min}$ \\
& 111In-pentetreotide & Planar, SPECT & $67 \mathrm{~h}$ \\
Glucose metabolism & 188Ga-DOTA-peptides & PET & $68 \mathrm{~min}$ \\
& & PET & $110 \mathrm{~min}$
\end{tabular}

(Pacak et al., 2001). First, the superiority of 18F-FDA over 131IMIBG in paragangliomas was demonstrated (Ilias et al., 2003). Subsequently 18F-FDA has been confirmed as an excellent imaging modality for the diagnosis and localization of both primary and metastatic sympathetic paragangliomas, with two studies demonstrating that in patients with non-metastatic paragangliomas $18 \mathrm{~F}$ FDA and 123I-MIBG have equivalent sensitivities for tumor detection, but in patients with metastatic disease 18F-FDA is superior to 123I-MIBG (Ilias et al., 2008; Timmers et al., 2009b). However, a previous study by Mamede et al. (2006) showed a lack of uptake of 18F-FDA in metastatic paragangliomas. It has been suggested that this resulted (as for 131/123I-MIBG) from cellular dedifferentiation, leading to a loss of specific cellular characteristics, like the expression of catecholamine transporters (this hypothesis will be further discussed in the next sub-section).

For parasympathetic head and neck paragangliomas, in contrast, the performance of $18 \mathrm{~F}-\mathrm{FDA}$ was found to be poor, as demonstrated in a prospective study by King et al. (2011) performed on SDHx-related head and neck paragangliomas (with an 18 F-FDA sensitivity of $46 \%$ by lesion and $40 \%$ by patient).

Some other shortfalls need to be mentioned concerning $18 \mathrm{~F}-$ FDA, some of which have already been mentioned in the section on 131/123I-MIBG. First, it has been suggested that some adrenergic stimulant products (like caffeine) could interfere with 18F-FDA; additional studies are currently evaluating this question. Also, due to the difficulty of production, 18F-FDA has limited availability. To our knowledge, there is only one producer in the world. Finally, physiologic uptake in normal adrenal glands may lead to falsepositive results. To address this physiologic uptake, the usefulness of standardized uptake values (SUV) to distinguish adrenal glands with pheochromocytoma from normal adrenal glands has been evaluated (Timmers et al., 2007b). The diagnosis of pheochromocytoma was estimated to be very unlikely if the SUV was under 7.3, whereas an SUV above 10.1 confirmed the presence of pheochromocytoma.

Recent papers studied the sensitivity of 18F-FDA specifically in particular genotypes. In a cohort of VHL mutation carriers, 18FFDA was demonstrated to be superior to 131/123I-MIBG (Kaji et al., 2007). Timmers et al. (2007c) studied 18F-FDA in a cohort of SDHB carriers and did not find any significant difference between 18F-FDA performance for SDHB-related and non-SDHB-related paragangliomas.

To summarize, 18F-FDA has already proven its excellent sensitivity in sympathetic paragangliomas, although additional study is necessary to determine its specificity in each genetic background. Its advantages compared to 123I-MIBG rely overall on the higher resolution and shorter time of acquisition. Additional studies are necessary to describe the differences on a molecular scale. Preferred 18F-FDA indications would be sympathetic nonhead and neck paragangliomas, except those related to the SDHB mutation.

\section{F-FDOPA}

18 F-FDOPA enters the cell via an amino acid transporter, the large amino acid transporter 2 (LAT2), undergoes decarboxylation by aromatic L-amino-acid decarboxylase (AADC), and is stored in secretory vesicles (Eisenhofer, 2004; Fiebrich et al., 2009). 


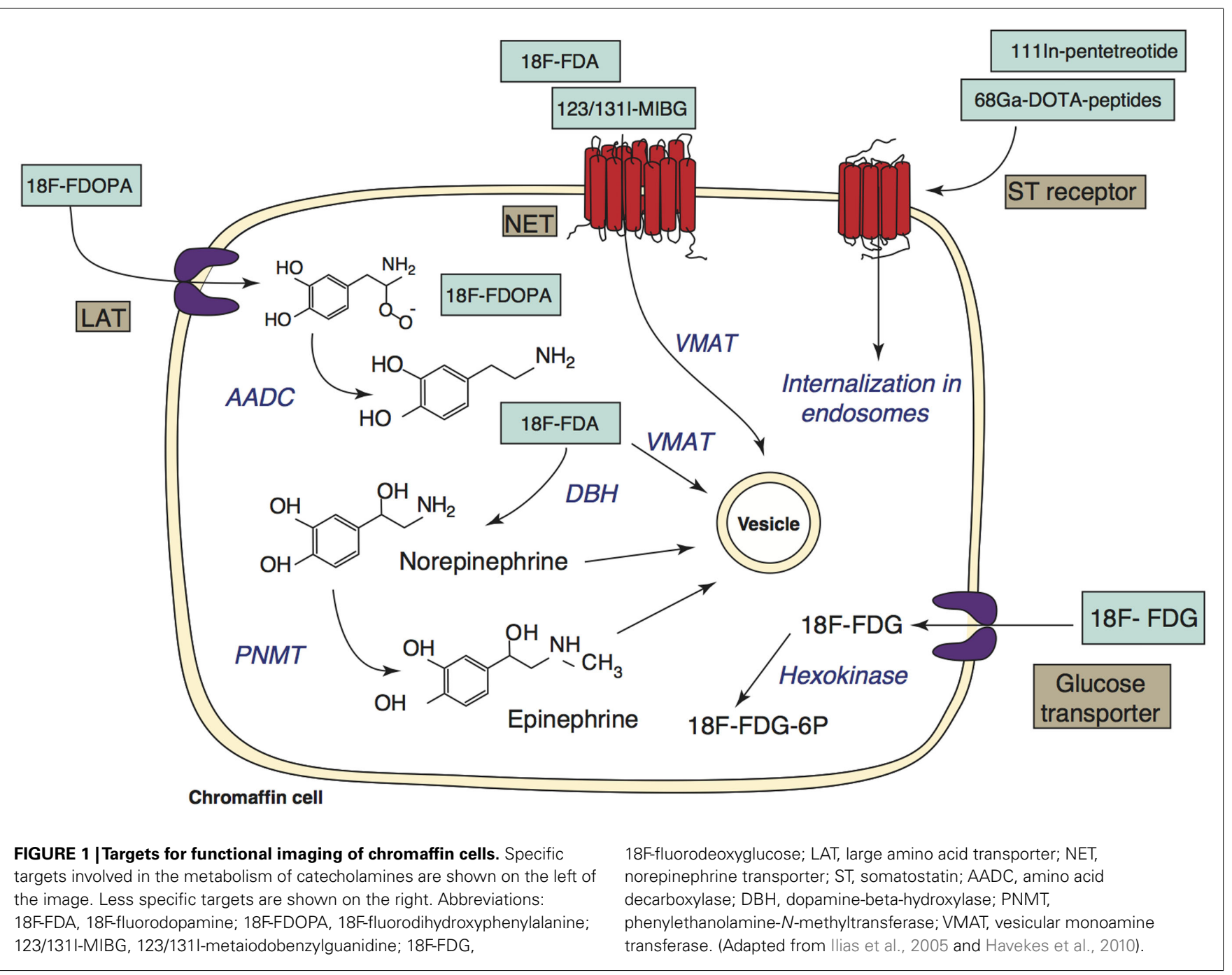

After being established as a tool for the localization of neuroendocrine tumors such as gastro-intestinal carcinoid tumors (Hoegerle et al., 2001; Becherer et al., 2004), 18F-FDOPA has been suggested as a good alternative for imaging in paragangliomas. Some studies focused specifically on head and neck paragangliomas and found an excellent sensitivity of 18F-FDOPA (Hoegerle et al., 2003; Charrier et al., 2011; King et al., 2011). In particular, a recent prospective study published by King et al., 2011; on 10 patients carrying SDHx mutation, with a total of 26 head and neck paragangliomas) found a $100 \%$ sensitivity of 18F-FDOPA.

In sympathetic paragangliomas, many studies have evaluated the accuracy of 18F-FDOPA (Taïeb et al., 2008; Fiebrich et al., 2009; Imani et al., 2009; Timmers et al., 2009a; Fottner et al., 2010; Rufini et al., 2011). 18F-FDOPA may have a very good sensitivity for primary adrenal pheochromocytomas (Imani et al., 2009). However, for primary extra-adrenal paragangliomas and metastatic paragangliomas, discrepant results are reported. Some studies showed very promising results, whereas others showed the presence of false negatives (Taïeb et al., 2008; Timmers et al., 2009a). Additional studies are necessary to explain these false negative lesions.
As with $18 \mathrm{~F}-\mathrm{FDA}$, there is a great deal of interest in the sensitivity of 18F-FDOPA in relation to specific genetic mutations. Timmers' study of patients with and without SDHB mutations found a high sensitivity for non-SDHB-related paragangliomas, but poor sensitivity for SDHB-related paragangliomas, especially for metastatic paragangliomas (Timmers et al., 2009a). Hoegerle's study on SDHD-related head and neck paragangliomas showed good 18F-FDOPA sensitivity (Hoegerle et al., 2003).

Carbidopa has been shown to enhance the sensitivity of 18FFDOPA for sympathetic paragangliomas by increasing the tumorto-background ratio of tracer uptake (Timmers et al., 2007d). However, in that study, the sensitivity of 18F-FDOPA for metastatic paragangliomas was still limited.

To conclude, 18F-FDOPA has excellent sensitivity in parasympathetic head and neck paragangliomas and should be used as first-line exam for these cases. For sympathetic paragangliomas, 18F-FDOPA may also have very good sensitivity in primary adrenal pheochromocytoma, but for metastatic and extra-adrenal paragangliomas, further studies need to be done. 


\section{F-FDG}

18F-FDG has been used for years in oncology and has also proved its usefulness in paragangliomas (Shulkin et al., 1999). This nonspecific tracer targets the glucose pathway of cells. It enters the cell via glucose transporters, undergoes phosphorylation by hexokinase to become 18F-FDG-6P, and is trapped in the cell. Thus its accumulation is an index of increased glucose metabolism.

Hence, as a marker of tumor viability, the degree of $18 \mathrm{~F}-\mathrm{FDG}$ uptake could reflect tumor aggressiveness. This hypothesis has been well-demonstrated in thyroid cancer, with studies showing an 18F-FDG uptake which is initially low or absent, but increased in the later stages of disease when cells are dedifferentiating (Feine et al., 1996; Grünwald et al., 1999; Helal et al., 2001). This is called a flip-flop phenomenon.

In paragangliomas, some studies have also found such a pattern (Mamede et al., 2006; Timmers et al., 2007c). However, a newer hypothesis has been proposed, that FDG uptake depends on the underlying genetic mutation (and the molecular phenomenon linked to these mutations). Indeed, some results did not fit with a flip-flop phenomenon, showing for example quasi-constant positivity of 18F-FDG in benign paragangliomas, which does not match with a well-differentiated tumor.

In parallel, basic science studies have found that oncogenetic signals resulting from mutations are present in both benign and malignant tumors. In particular, pseudo-hypoxic signatures are found in SDHx/VHL tumors, with upregulation of (HIF)-1alpha target genes involved in angiogenesis, proliferation, apoptosis, invasion, and energy metabolism (Favier and Gimenez-Roqueplo, 2010).

Interesting studies have been done to study $18 \mathrm{~F}-\mathrm{FDG}$ performance specifically in each genetic group. For SDHB-related paragangliomas, 18F-FDG has been shown to have an excellent sensitivity with a particularly high uptake (Timmers et al., 2007c; Zelinka et al., 2008; Taïeb et al., 2009). This has been partially explained by interpreting the molecular mechanism occurring in SDHB-mutated cells. The SDHB gene codes for subunit B of the mitochondrial SDH complex. This complex is involved in two essential energy-producing metabolic processes of the cells: the tricyclic acid (TCA) cycle and the electron transport respiratory chain (oxidative phosphorylation). Mutation of the SDHB gene results in a loss of function of the SDH complex. This could thus impair energy production, causing the cells to switch to a less efficient pathway (glycolysis) for energy production. The consequence is the augmentation of glucose uptake via glucose transporters. This phenomenon is called the Warburg effect (Warburg, 1956).

Additional studies are necessary to explore $18 \mathrm{~F}-\mathrm{FDG}$ performance in other SDHx-related paragangliomas (which also feature a loss of function of the SDH complex), as well as in VHLrelated paragangliomas, in which the Warburg effect also seems to occur (Favier et al., 2009). Moreover, the link between the pseudohypoxic signature in VHL- and SDHx-related paragangliomas and PET imaging still needs to be studied further.

Besides its role in locating and understanding paragangliomas, 18F-FDG could be useful for monitoring therapeutic response (like in lymphomas). Timmers et al. (2007c) found an excellent sensitivity of 18 F-FDG after chemotherapy and 131I-MIBG therapy, and suggested that $18 \mathrm{~F}-\mathrm{FDG}$ could be used for treatment monitoring of malignant paragangliomas. A case report published by $\mathrm{He}$ et al. (2009) showed a strong correlation between initial 18F-FDG uptake and the clinical response of a patient undergoing chemotherapy for metastatic paraganglioma, and suggested that it would be interesting to perform studies evaluating the ability of 18F-FDG to select tumors more likely to respond to chemotherapy. On a recent study of 11 patients with malignant paragangliomas who underwent 131I-MIBG therapy, Nakazawa et al. (2011) evaluated the change in SUV from pre- to post-therapy, and showed that $18 \mathrm{~F}-\mathrm{FDG}$ could be a promising tool to monitor the response of malignant paragangliomas to $131 \mathrm{I}-\mathrm{MIBG}$ therapy.

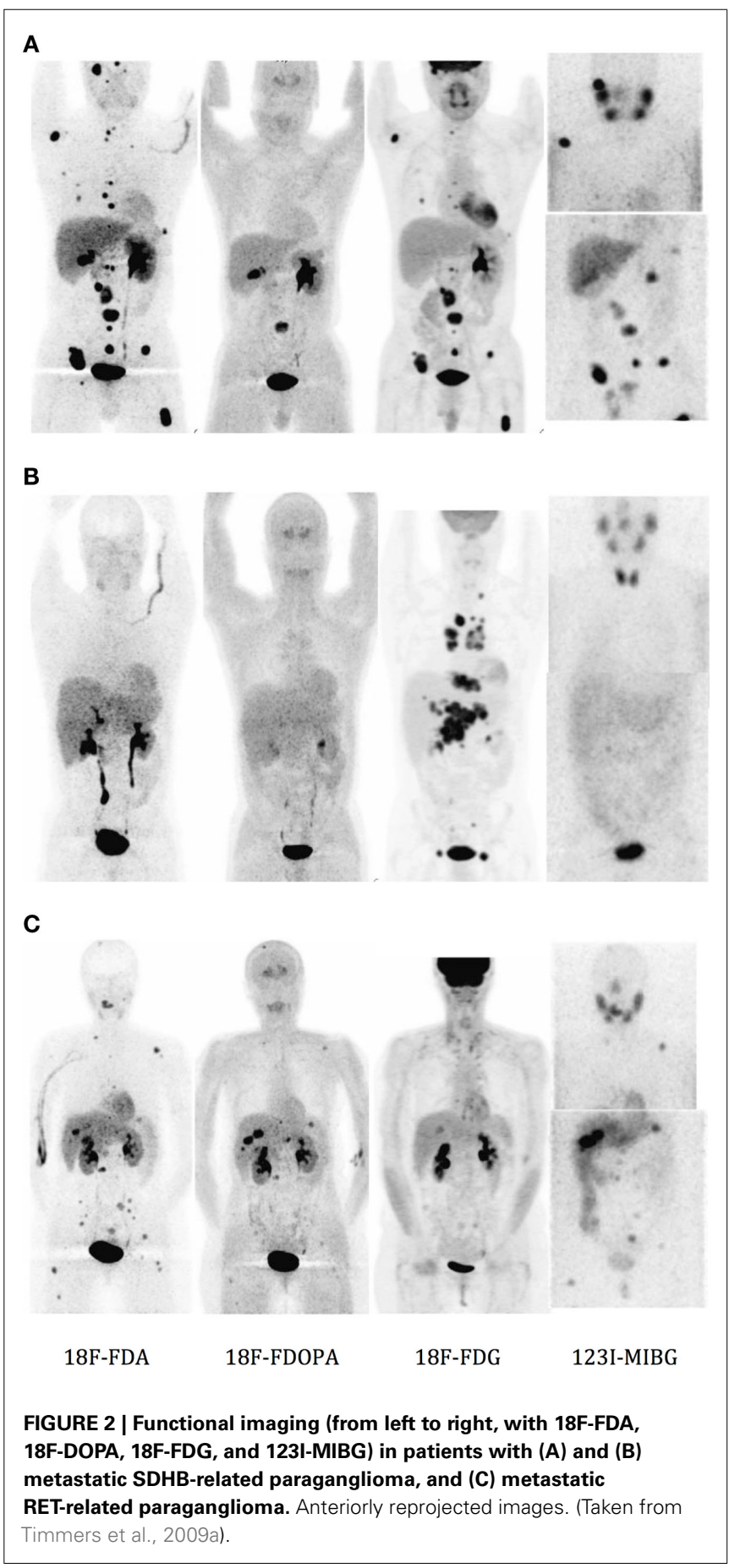


Table 2 | Suggested functional imaging modalities for paragangliomas, in relation to genetic background and location of primary tumor.

\begin{tabular}{|c|c|c|c|}
\hline Genetic background: & SDHB & Non-SDHB & Unknown \\
\hline $\begin{array}{l}\text { Predisposition to } \\
\text { metastases: }\end{array}$ & High & $\begin{array}{l}\text { Low for adrenal paragangliomas, higher for } \\
\text { extra-adrenal paragangliomas }\end{array}$ & $\begin{array}{l}\text { Low for adrenal paragangliomas, higher for } \\
\text { extra-adrenal paragangliomas }\end{array}$ \\
\hline Head and neck & $\begin{array}{l}\text { 18F-FDG or } \\
18 F-F D O P A\end{array}$ & $\begin{array}{l}\text { 18F-FDOPA as first-line, } \\
\text { 18F-FDG (if 18F-FDOPA is not available), } \\
111 \mathrm{ln} \text {-pentetreotide (if PET is not available), } \\
68 \mathrm{Ga}-D O T A-p e p t i d e s \text { (experimental) }\end{array}$ & $\begin{array}{l}\text { 18F-FDOPA as first-line, } \\
\text { 18F-FDG (if 18F-FDOPA is not available), } \\
111 \text { In-pentetreotide (if PET is not available), } \\
68 \mathrm{Ga}-D O T A-p e p t i d e s \text { (experimental) }\end{array}$ \\
\hline Sympathetic & $\begin{array}{l}\text { 18F-FDG or } \\
18 F-F D A\end{array}$ & $\begin{array}{l}\text { 18F-FDA or } 18 \text { F-FDOPA*, } \\
123 \text { I-MIBG (if PET is not available) }\end{array}$ & $\begin{array}{l}\text { 18F-FDA as first-line, } \\
\text { 18F-FDOPA or } 123 \mathrm{I} \text {-MIBG (if } 18 \mathrm{~F}-\mathrm{FDA} \text { is not available) }\end{array}$ \\
\hline
\end{tabular}

*18F-FDA was found to be more sensitive than F-FDOPA in the detection of metastases (Timmers et al., 2009b).

In summary, 18F-FDG is very useful in imaging paragangliomas, not only for localization, but also for understanding the disease overall. It should be used as first-line exam in SDHBrelated paragangliomas. More studies need to be done on other genetic patterns.

Regarding all the PET tracers discussed above, imaging of three different patients from a publication of Timmers et al. (2009a), is shown on Figure 2.

\section{Ga-D0TA-PEPTIDES}

111In-pentetreotide has been described earlier as an SSR ligand, and we have pointed out its limitation due to the lack of affinity with some receptor subtypes. Newer somatostatin analogs, 68Ga-DOTA-Tyr3-octreotide (DOTATOC; Buchmann et al., 2007; Kroiss et al., 2011), 68Ga-DOTANOC (Wild et al., 2004), and 68Ga-DOTA-TATE (Win et al., 2007; Naji et al., 2011) have shown favorable characteristics in imaging, with a high affinity for SSRs and a stable and easy process of labeling. They have shown promising results in imaging SSR-positive tumors as compared to nonPET 111In-pentetreotide scintigraphy, highlighting the superior performance of PET imaging over scintigraphy in general. These newer PET imaging modalities still await further evaluation.

\section{C-HYDROXYEPHEDRINE}

11C-hydroxyephedrine (11C-HED) is more polar than MIBG and has even greater similarities with norepinephrine. It was the first positron-emitting probe of the sympathoadrenal system used on humans (Shulkin et al., 1992). However the synthesis is complex, and its very short half-life $(20 \mathrm{~min})$ makes on-site production a requirement for each patient. Consequently it has not been developed as a routine imaging technique.

\section{I-MIBG}

Iodine 124 (124I) is a positron emitter with promise for clinical PET imaging, especially for imaging and for pretherapy dosimetry of Iodine 131 treatment in thyroid cancer. Few studies have been performed with 124I-labeled MIBG. Ott et al. (1992) used it to predict the absorbed dose of 131I-MIBG in neural crest tumor sites of two patients. The advantage of 124I-MIBG PET over 123IMIBG scintigraphy relies on the ability to obtain more accurate quantification of tracer distribution. The main problem limiting its use in human is the radiation exposure, since $124 \mathrm{I}$ has a half-life of 4 days (which is much longer than $18 \mathrm{~F}$ and $68 \mathrm{Ga}$ ).
To assess this problem, Lee performed an estimation of the absorbed radiation dose with 124I-MIBG using preclinical small animal models. He concluded that the use of 124I-MIBG is safe as long as a relatively small amount of radioactivity is used. This tracer should be used only when 131I-MIBG therapy is planned. In this case, the pretherapy imaging dose would be negligible by comparison (Lee et al., 2010). The prospect could then be to use 124I-MIBG for imaging and for pretherapy dosimetry in order to improve the efficacy and safety of 131I-MIBG therapy.

We summarize suggested functional imaging modalities for paragangliomas in Table 2.

\section{CONCLUSION}

Because of the specific cellular characteristics of paragangliomas and the rapidly growing knowledge on their genetic background, functional imaging, in addition to its role in diagnosis, localization, and ruling out of metastases, has a crucial place for understanding tumor behavior (aggressiveness, potential to metastasize, pathophysiology, and response to therapy). Thanks to the development of PET imaging, we have the tools to perform it.

To date, probably because of the rarity of this disease, few studies have been done on homogeneous groups. More studies are needed to study the performances of each functional imaging modality in relation to underlying genetic mutations. This would allow each patient to receive an optimal diagnostic and therapeutic approach, adapted to the specific pattern of paraganglioma.

In the meantime, we suggest the first-line exam choice to be as follows: for SDHB-related paragangliomas, 18F-FDG; for nonSDHB sympathetic paragangliomas, 18F-FDA (or 18F-FDOPA in adrenal paragangliomas); and for parasympathetic head and neck paragangliomas, 18F-FDOPA.

Another goal in future imaging studies would be to be able to predict response to therapy, and to follow up disease under treatment. In addition, new non-specific tracers are still awaited, in particular targeting other molecular phenomena such as angiogenesis, proliferation, apoptosis, and hypoxia. This would help to understand molecular oncogenic pathways in paragangliomas, particularly the (HIF)-1alpha pathway.

\section{ACKNOWLEDGMENTS}

This research was supported, in part, by the Intramural Research Program of the National Institute of Child Health and Human Development, National Institutes of Health. 


\section{REFERENCES}

Amar, L., Baudin, E., Burnichon, N., Peyrard, S., Silvera, S., Bertherat, J., Bertagna, X., Schlumberger, M., Jeunemaitre, X., GimenezRoqueplo, A. P., and Plouin, P. F. (2007). Succinate dehydrogenase $B$ gene mutations predict survival in patients with malignant pheochromocytomas or paragangliomas. J. Clin. Endocrinol. Metab. 92, 3822-3828.

Amar, L., Bertherat, J., Baudin, E., Ajzenberg, C., Bressac-de Paillerets, B., Chabre, O., Chamontin, B., Chamontin, B., Delemer, B., Giraud, S., Murat, A., Niccoli-Sire, P., Richard, S., Rohmer, V., Sadoul, J. L., Strompf, L., Schlumberger, M., Bertagna, X., Plouin, P. F., Jeunemaitre, X., and Gimenez-Roqueplo, A. P. (2005). Genetic testing in pheochromocytoma or functional paraganglioma. J. Clin. Oncol. 23, 8812-8818.

Becherer, A., Szabó, M., Karanikas, G., Wunderbaldinger, P., Angelberger, P., Raderer, M., Kurtaran, A., Dudczak, R., and Kletter, K. (2004). Imaging of advanced neuroendocrine tumors with (18)F-FDOPA PET. J. Nucl. Med. 45, 1161-1167.

Bryant, J., Farmer, J., Kessler, L. J., Townsend, R. R., and Nathanson, K. L. (2003). Pheochromocytoma: the expanding genetic differential diagnosis. J. Natl. Cancer Inst. 95, 1196-1204.

Buchmann, I., Henze, M., Engelbrecht, S., Eisenhut, M., Runz, A., Schäfer, M., Schilling, T., Haufe, S., Herrmann, T., and Haberkorn, U. (2007). Comparison of $68 \mathrm{Ga}$-DOTATOC PET and 111In-DTPAOC (Octreoscan) SPECT in patients with neuroendocrine tumours. Eur. J. Nucl. Med. Mol. Imaging 34, 1617-1626.

Burnichon, N., Brière, J.-J., Libé, R., Vescovo, L., Rivière, J., Tissier, F., Jouanno, E., Jeunemaitre, X., Bénit, P., Tzagoloff, A., Rustin, P., Bertherat, J., Favier, J., and Gimenez-Roqueplo, A. P.(2010). SDHA is a tumor suppressor gene causing paraganglioma. Hum. Mol. Genet. 19, 3011-3020.

Cecchin, D., Lumachi, F., Marzola, M. C., Opocher, G., Scaroni, C., Zucchetta, P., Mantero, F., and Bui, F. (2006). A metaiodobenzylguanidine scintigraphic scoring system increases accuracy in the diagnostic management of pheochromocytoma. Endocr. Relat. Cancer 13, 525-533.

Charrier, N., Deveze, A., Fakhry, N., Sebag, F., Morange, I., Gaborit, B., Barlier, A., Carmona, E., De Micco, C., Garcia, S., Mancini,
J., Palazzo, F. F., Lavieille, J. P., Zanaret, M., Henry, J. F., Mundler, O., and Taïeb, D. (2011). Comparison of $\left[{ }^{111} \mathrm{In}\right]$ pentetreotide-SPECT and $\left[{ }^{18} \mathrm{~F}\right]$ FDOPA-PET in the localization of extra-adrenal paragangliomas: the case for a patienttailored use of nuclear imaging modalities. Clin. Endocrinol. (Oxf.) 74, 21-29.

Comino-Méndez, I., Gracia-Aznárez, F. J., Schiavi, F., Landa, I., LeandroGarcía, L. J., Letón, R., Honrado, E., Ramos-Medina, R., Caronia, D., Pita, G., Gómez-Graña, A., de Cubas, A. A., Inglada-Pérez, L., Maliszewska, A., Taschin, E., Bobisse, S., Pica, G., Loli, P., Hernández-Lavado, R., Díaz, J. A., Gómez-Morales, M., González-Neira, A., Roncador, G., Rodríguez-Antona, C., Benítez, J., Mannelli, M., Opocher, G., Robledo, M., and Cascón, A. (2011). Exome sequencing identifies MAX mutations as a cause of hereditary pheochromocytoma. Nature 43, 663-667.

de Herder, W., and Lamberts, S. (2002). Somatostatin and somatostatin analogues: diagnostic and therapeutic uses. Curr. Opin. Oncol. 14, 53-57.

DeLellis, R. A. (2004). Pathology and Genetics of Tumours of Endocrine Organs. Lyon: World Health Organization, 320.

Eisenhofer, G. (2001). The role of neuronal and extraneuronal plasma membrane transporters in the inactivation of peripheral catecholamines. Pharmacol. Ther. 91, 35-62.

Eisenhofer, G. (2004). Catecholamine metabolism: a contemporary view with implications for physiology and medicine. Pharmacol. Rev. 56, 331-349.

Favier, J., Brière, J.-J., Burnichon, N., Rivière, J., Vescovo, L., Benit, P., Giscos-Douriez, I., De Reyniès, A., Bertherat, J., Badoual, C., Tissier, F., Amar, L., Libé, R., Plouin, P. F., Jeunemaitre, X., Rustin, P., and Gimenez-Roqueplo, A. P. (2009). The Warburg effect is genetically determined in inherited pheochromocytomas. PLoS ONE 4, e7094. doi:10.1371/journal.pone.0007094

Favier, J., and Gimenez-Roqueplo, A. P. (2010). Pheochromocytomas: the (pseudo)-hypoxia hypothesis. Best Pract. Res. Clin. Endocrinol. Metab. 24, 957-968.

Feine, U., Lietzenmayer, R., Hanke, J. P., Held, J., Wöhrle, H., and Müller-Schauenburg, W. (1996). Fluorine-18-FDG and iodine-131iodide uptake in thyroid cancer. $J$. Nucl. Med. 37, 1468-1472.
Fiebrich, H.-B., Brouwers, A. H., Kerstens, M. N., Pijl, M. E. J., Kema, I. P., de Jong, J. R., Jager, P. L., Elsinga, P. H., Dierckx, R. A., van der Wal, J. E., Sluiter, W. J., de Vries, E. G., and Links, T. P. (2009). 6-[F-18]FluoroL-dihydroxyphenylalanine positron emission tomography is superior to conventional imaging with (123)Imetaiodobenzylguanidine scintigraphy, computer tomography, and magnetic resonance imaging in localizing tumors causing catecholamine excess. J. Clin. Endocrinol. Metab. 94, 3922-3930.

Fottner, C., Helisch, A., Anlauf, M., Rossmann, H., Musholt, T J., Kreft, A., Schadmand-Fischer, S., Bartenstein, P., Lackner, K. J., Klöppel, G., Schreckenberger, M., and Weber, M. M. (2010). 6-18F-fluoro-Ldihydroxyphenylalanine positron emission tomography is superior to 123I-metaiodobenzyl-guanidine scintigraphy in the detection of extraadrenal and hereditary pheochromocytomas and paragangliomas: correlation with vesicular monoamine transporter expression. J. Clin. Endocrinol. Metab. 95, 2800-2810.

Gimenez-Roqueplo, A.-P., Burnichon, N., Amar, L., Favier, J., Jeunemaitre, X., and Plouin, P.-F. (2008). Recent advances in the genetics of pheochromocytoma and functional paraganglioma. Clin. Exp. Pharmacol. Physiol. 35, 376-379.

Gimenez-Roqueplo, A.-P., Favier, J., Rustin, P., Rieubland, C., Crespin, M., Nau, V., Khau Van Kien, P., Corvol, P., Plouin, P. F., Jeunemaitre, X., and COMETE Network. (2003). Mutations in the SDHB gene are associated with extra-adrenal and/or malignant phaeochromocytomas. Cancer Res. 63, 5615-5621.

Gimenez-Roqueplo, A.-P., Lehnert, H., Mannelli, M., Neumann, H., Opocher, G., Maher, E. R., and Plouin, P. F. (2006). Phaeochromocytoma, new genes and screening strategies. Clin. Endocrinol. (Oxf.) 65, 699-705.

Grünwald, F., Kälicke, T., Feine, U., Lietzenmayer, R., Scheidhauer, K., Dietlein, M., Schober, O., Lerch, H., Brandt-Mainz, K., Burchert, W., Hiltermann, G., Cremerius, U., and Biersack, H. J. (1999). Fluorine-18 fluorodeoxyglucose positron emission tomography in thyroid cancer: results of a multicentre study. Eur. J. Nucl. Med. 26, 1547-1552.

Hao, H.-X., Khalimonchuk, O., Schraders, M., Dephoure, N., Bayley, J.-P., Kunst, H., Devilee, P., Cremers, C. W., Schiffman, J. D., Bentz, B. G.,
Gygi, S. P., Winge, D. R., Kremer, H., and Rutter, J. (2009). SDH5, a gene required for flavination of succinate dehydrogenase, is mutated in paraganglioma. Science 325, 1139-1142.

Havekes, B., King, K., Lai, E. W., Romijn, J. A., Corssmit, E. P. M., and Pacak, K. (2010). New imaging approaches to phaeochromocytomas and paragangliomas. Clin. Endocrinol. 72, 137-145.

He, J., Makey, D., Fojo, T., Adams, K., and Havekes, B. (2009). Successful chemotherapy of hepatic metastases in a case of succinate dehydrogenase subunit B-related paraganglioma. Endocrine 36, 189-193.

Helal, B. O., Merlet, P., Toubert, M. E., Franc, B., Schvartz, C., GauthierKoelesnikov, H., Prigent, A., and Syrota, A. (2001). Clinical impact of (18)F-FDG PET in thyroid carcinoma patients with elevated thyroglobulin levels and negative (131)I scanning results after therapy. $J$. Nucl. Med. 42, 1464-1469.

Hoegerle, S., Altehoefer, C., Ghanem, N., Koehler, G., Waller, C. F., Scheruebl, H., Moser, E., and Nitzsche, E. (2001). Whole-body 18F dopa PET for detection of gastrointestinal carcinoid tumors. Radiology 220, 373-380.

Hoegerle, S., Ghanem, N., Altehoefer, C., Schipper, J., Brink, I., Moser, E., and Neumann, H. (2003). 18F-DOPA positron emission tomography for the detection of glomus tumours. Eur. J. Nucl. Med. Mol. Imaging 30, 689-694.

Ilias, I., Chen, C. C., Carrasquillo, J. A., Whatley, M., Ling, A., Lazúrová, I., Adams, K. T., Perera, S., and Pacak, K. (2008). Comparison of 6-18F-fluorodopamine PET with 123I-metaiodobenzylguanidine and 111 in-pentetreotide scintigraphy in localization of nonmetastatic and metastatic pheochromocytoma. J. Nucl. Med. 49, 1613-1619.

Ilias, I., Juan, Y. U., Carrasquillo, J. A., Chen, C. C., Eisenhofer, G., Whatley, M., McElroy, B., and Pacak, K. (2003). Superiority of 6-[18F]-fluorodopamine positron emission tomography versus [131I]-metaiodobenzylguanidine scintigraphy in the localization of metastatic pheochromocytoma. J. Clin. Endocrinol. Metab. 88, 4083-4087.

Ilias, I., Shulkin, B., and Pacak, K. (2005). New functional imaging modalities for chromaffin tumors, neuroblastomas and ganglioneuromas. Trends Endocrinol. Metab. 16, 66-72. 
Imani, F., Agopian, V. G., Auerbach, M. S., Walter, M. A., Imani, F., Benz, M. R., Dumont, R. A., Lai, C. K., Czernin, J. G., and Yeh, M. W. (2009). 18F-FDOPA PET and PET/CT accurately localize pheochromocytomas. J. Nucl. Med. 50, 513-519.

Kaji, P., Carrasquillo, J. A., Linehan, W. M., Chen, C. C., Eisenhofer, G., Pinto, P. A., Lai, E. W., and Pacak, K. (2007). The role of $6-[18 \mathrm{~F}]$ fluorodopamine positron emission tomography in the localization of adrenal pheochromocytoma associated with von HippelLindau syndrome. Eur. J. Endocrinol. $156,483-487$.

King, K. S., Chen, C. C., Alexopoulos, D. K., Whatley, M. A., Reynolds, J. C., Patronas, N., Ling, A., Adams, K. T., Xekouki, P., Lando, H., Stratakis, C. A., and Pacak, K. (2011). Functional imaging of SDHx-related head and neck paragangliomas: comparison of 18F-Fluorodihydroxyphenylalani ne, $18 \mathrm{~F}$-fluorodopamine, $18 \mathrm{~F}-\mathrm{flu}$ oro-2-deoxy-D-glucose PET, 123Imetaiodobenzylguanidine scintigraphy, and 111In-pentetreotide scintigraphy. J. Clin. Endocrinol. Metab. 96, 2779-2785.

Koopmans, K. P., Jager, P. L., Kema, I. P., Kerstens, M. N., Albers, F., and Dullaart, R. P. F. (2008). 111Inoctreotide is superior to $123 \mathrm{I}$ metaiodobenzylguanidine for scintigraphic detection of head and neck paragangliomas. J. Nucl. Med. 49, 1232-1237.

Kroiss, A., Putzer, D., Uprimny, C., Decristoforo, C., Gabriel, M., Santner, W., Kranewitter, C., Warwitz, B., Waitz, D., Kendler, D., and Virgolini, I. J. (2011). Functional imaging in phaeochromocytoma and neuroblastoma with $68 \mathrm{Ga}-$ DOTA-Tyr 3-octreotide positron emission tomography and 123Imetaiodobenzylguanidine. Eur. J. Nucl. Med. Mol. Imaging 38, 865-873.

Lamberts, S. W., Reubi, J. C., and Krenning, E. P. (1993). Validation of somatostatin receptor scintigraphy in the localization of neuroendocrine tumors. Acta Oncol. 32, 167-170.

Lee, C.-L., Wahnishe, H., Sayre, G. A., Cho, H.-M., Kim, H.J., Hernandez-Pampaloni, M., Hawkins, R. A., Dannoon, S. F., VanBrocklin, H. F., Itsara, M., Weiss, W. A., Yang, X., Haas-Kogan, D. A., Matthay, K. K., and Seo, Y. (2010). Radiation dose estimation using preclinical imaging with 124I-metaiodobenzylguanidine
(MIBG) PET. Med. Phys. 37, 4861-4867.

Lynn, M. D., Shapiro, B., Sisson, J. C., Beierwaltes, W. H., Meyers, L. J., Ackerman, R., and Mangner, T. J. (1985). Pheochromocytoma and the normal adrenal medulla: improved visualization with I-123 MIBG scintigraphy. Radiology 155, 789-792.

Mamede, M., Carrasquillo, J. A., Chen, C. C., Del Corral, P., Whatley, M., Ilias, I., Ayala, A., and Pacak, K. (2006). Discordant localization of 2-[18F]-fluoro2-deoxy-D-glucose in 6-[18F]fluorodopamine and [(123)I]metaiodobenzylguanidine-negative metastatic pheochromocytoma sites. Nucl. Med. Commun. 27, 31-36.

Naji, M., Zhao, C., Welsh, S. J., Meades, R., Win, Z., Ferrarese, A., Tan, T., Rubello, D., and Al-Nahhas, A. (2011). 68Ga-DOTA-TATE PET vs. 123I-MIBG in identifying malignant neural crest tumours. Mol. Imaging Biol. 13, 769-775.

Nakazawa, A., Higuchi, T., Oriuchi, N., Arisaka, Y., and Endo, K. (2011). Clinical significance of 2-[18F]fluoro-2-deoxy-D-glucose positron emission tomography for the assessment of 131Imetaiodobenzylguanidine therapy in malignant phaeochromocytoma. Eur. J. Nucl. Med. Mol. Imaging 38, 1869-1875.

Neumann, H. P. H., Pawlu, C., Peczkowska, M., Bausch, B., McWhinney, S. R., Muresan, M., Buchta, M., Franke, G., Klisch, J., Bley, T. A., Hoegerle, S., Boedeker, C. C., Opocher, G., Schipper, J., Januszewicz, A., and Eng C, European-American Paraganglioma Study Group. (2004). Distinct clinical features of paraganglioma syndromes associated with SDHB and SDHD gene mutations. JAMA 292, 943-951.

Ott, R. J., Tait, D., Flower, M. A., Babich, J. W., and Lambrecht, R. M. (1992). Treatment planning for 131I-mIBG radiotherapy of neural crest tumours using 124I-mIBG positron emission tomography. Br. J. Radiol. 65, 787-791.

Pacak, K., Eisenhofer, G., Carrasquillo, J. A., Chen, C. C., Li, S. T., and Goldstein, D. S. (2001). 6$[18 \mathrm{~F}]$ fluorodopamine positron emission tomographic (PET) scanning for diagnostic localization of pheochromocytoma. Hypertension $38,6-8$.

Qin, Y., Yao, L., King, E. E., Buddavarapu, K., Lenci, R. E., Chocron, E. S., Lechleiter, J. D., Sass, M., Aronin, N.,
Schiavi, F., Boaretto, F., Opocher, G., Toledo, R. A., Toledo, S. P., Stiles, C. Aguiar, R. C., and Dahia, P. L. (2010) Germline mutations in TMEM127 confer susceptibility to pheochromocytoma. Nature 42, 229-233.

Reubi, J. C., Waser, B., Khosla, S., Kvols, L., Goellner, J. R., Krenning, E., Lamberts, S. (1992). In vitro and in vivo detection of somatostatin receptors in pheochromocytomas and paragangliomas. J. Clin. Endocrinol. Metab. 74, 1082-1089.

Rufini, V., Treglia, G., Castaldi, P., Perotti, G., Calcagni, M. L., Corsello, S. M., Galli, G., Fanti, S., and Giordano, A. (2011). Comparison of 123IMIBG SPECT-CT and 18F-DOPA PET-CT in the evaluation of patients with known or suspected recurrent paraganglioma. Nucl. Med. Commun. 32, 575-582.

Shulkin, B. L., Shapiro, B., Francis, I. R., Dorr, R., Shen, S. W., and Sisson, J. C. (1986). Primary extra-adrenal pheochromocytoma: positive I-123 MIBG imaging with negative I-131 MIBG imaging. Clin. Nucl. Med. 11 , 851-854.

Shulkin, B. L., Thompson, N. W., Shapiro, B., Francis, I. R., and Sisson, J. C. (1999). Pheochromocytomas: imaging with 2-[fluorine-18]fluoro2-deoxy-D-glucose PET. Radiology $212,35-41$

Shulkin, B. L., Wieland, D. M., Schwaiger, M., Thompson, N. W. Francis, I. R., Haka, M. S., Rosenspire, K. C., Shapiro, B., Sisson, J. C., and Kuhl, D. E. (1992). PET scanning with hydroxyephedrine: an approach to the localization of pheochromocytoma. J. Nucl. Med. 33, 1125-1131.

Sisson, J. C., Frager, M. S., Valk, T. W., Gross, M. D., Swanson, D. P., Wieland, D. M., Tobes, M. C., Beierwaltes, W. H., and Thompson, N. W. (1981). Scintigraphic localization of pheochromocytoma. N. Engl. J. Med. $305,12-17$.

Solanki, K. K., Bomanji, J., Moyes, J., Mather, S. J., Trainer, P. J., and Britton, K. E. (1992). A pharmacological guide to medicines which interfere with the biodistribution of radiolabelled meta-iodobenzylguanidine (MIBG). Nucl. Med. Commun. 13 513-521.

Taïeb, D., Sebag, F., Barlier, A., Tessonnier, L., Palazzo, F. F., Morange, I., Niccoli-Sire, P., Fakhry, N., De Micco, C., Cammilleri, S., Enjalbert, A., Henry, J. F., and Mundler, O. (2009). 18F-FDG avidity of pheochromocytomas and paragangliomas: a new molecular imaging signature. J. Nucl. Med. 50, 711-717.
Taïeb, D., Tessonnier, L., Sebag, F., Niccoli-Sire, P., Morange, I., Colavolpe, C., De Micco, C., Barlier, A., Palazzo, F. F., Henry, J. F., and Mundler, O. (2008). The role of 18F-FDOPA and 18F-FDG-PET in the management of malignant and multifocal phaeochromocytomas. Clin. Endocrinol. (Oxf.) 69, 580-586.

Timmers, H. J. L. M., Chen, C. C., Carrasquillo, J. A., Whatley, M., Ling, A., Havekes, B., Eisenhofer, G., Martiniova, L., Adams, K. T., and Pacak, K. (2009a). Comparison of 18F-fluoroL-DOPA, 18F-fluoro-deoxyglucose, and $18 \mathrm{~F}$-fluorodopamine PET and 123I-MIBG scintigraphy in the localization of pheochromocytoma and paraganglioma. J. Clin. Endocrinol. Metab. 94, 4757-4767.

Timmers, H. J. L. M., Eisenhofer, G., Carrasquillo, J. A., Chen, C. C., Whatley, M., Ling, A., Adams, K. T., and Pacak, K. (2009b). Use of 6-[18F]-fluorodopamine positron emission tomography (PET) as firstline investigation for the diagnosis and localization of non-metastatic and metastatic phaeochromocytoma (PHEO). Clin. Endocrinol. (Oxf.) 71, 11-17.

Timmers, H. J. L. M., Kozupa, A., Eisenhofer, G., Raygada, M., Adams, K. T., Solis, D., Lenders, J. W. M., and Pacak, K. (2007a). Clinical presentations, biochemical phenotypes, and genotype-phenotype correlations in patients with succinate dehydrogenase subunit B-associated pheochromocytomas and paragangliomas. J. Clin. Endocrinol. Metab. 92, 779-786.

Timmers, H. J. L. M., Carrasquillo, J. A., Whatley, M., Eisenhofer, G., Chen, C. C., Ling, A., Linehan, W. M., Pinto, P. A., Adams, K. T., and Pacak, K. (2007b). Usefulness of standardized uptake values for distinguishing adrenal glands with pheochromocytoma from normal adrenal glands by use of 6-18F-fluorodopamine PET. J. Nucl. Med. 48, 1940-1944.

Timmers, H. J. L. M., Kozupa, A., Chen, C. C., Carrasquillo, J. A., Ling, A., Eisenhofer, G., Adams, K. T., Solis, D., Lenders, J. W., and Pacak, K. (2007c). Superiority of fluorodeoxyglucose positron emission tomography to other functional imaging techniques in the evaluation of metastatic SDHBassociated pheochromocytoma and paraganglioma. J. Clin. Oncol. 25, 2262-2269.

Timmers, H. J. L. M., Hadi, M., Carrasquillo, J. A., Chen, C. C., Martiniova, L., Whatley, M., Ling, A., Eisenhofer, G., Adams, K. T., and 
Pacak, K. (2007d). The effects of carbidopa on uptake of 6-18F-fluoroL-DOPA in PET of pheochromocytoma and extraadrenal abdominal paraganglioma. J. Nucl. Med. 48, 1599-1606.

Tischler, A. S. (2008). Pheochromocytoma: time to stamp out "malignancy.” Endocr. Pathol. 19, 207-208.

van der Harst, E., de Herder, W. W., Bruining, H. A., Bonjer, H. J., de Krijger, R. R., Lamberts, S. W., van de Meiracker, A. H., Boomsma, F., Stijnen, T., Krenning, E. P., Bosman, F. T., Kwekkeboom, D. J. (2001). [(123)I] metaiodobenzylguanidine and [(111)In]octreotide uptake in begnign and malignant pheochromocytomas. J. Clin. Endocrinol. Metabol. 86, 685-693.

Warburg, O. (1956). On the origin of cancer cells. Science 123, 309-314.
Wild, D., Mäcke, H. R., Waser, B., Reubi, J. C., Ginj, M., Rasch, H., MüllerBrand, J., and Hofmann, M. (2004). 68Ga-DOTANOC: a first compound for PET imaging with high affinity for somatostatin receptor subtypes 2 and 5. Eur. J. Nucl. Med. Mol. Imaging 32, 724.

Win, Z., Al-Nahhas, A., Towey, D., Todd, J. F., Rubello, D., Lewington, V., and Gishen, P. (2007). 68Ga-DOTATATE PET in neuroectodermal tumours: first experience. Nucl. Med. Commun. 28, 359-363.

Wiseman, G. A., Pacak, K., O’Dorisio, M. S., Neumann, D. R., Waxman, A. D., Mankoff, D. A., Heiba, S. I., Serafini, A. N., Tumeh, S. S., Khutoryansky, N., and Jacobson, A. F. (2009). Usefulness of 123IMIBG scintigraphy in the evaluation of patients with known or suspected primary or metasta- tic pheochromocytoma or paraganglioma: results from a prospective multicenter trial. J. Nucl. Med. 50, 1448-1454.

Zelinka, T., Timmers, H. J. L. M., Kozupa, A., Chen, C. C., Carrasquillo, J. A., Reynolds, J. C., Ling, A., Eisenhofer, G., Lazúrová, I., Adams, K. T., Whatley, M. A., Widimsky, J. Jr., and Pacak, K. (2008). Role of positron emission tomography and bone scintigraphy in the evaluation of bone involvement in metastatic pheochromocytoma and paraganglioma: specific implications for succinate dehydrogenase enzyme subunit B gene mutations. Endocr. Relat. Cancer 15, 311-323.

Conflict of Interest Statement: The authors declare that the research was conducted in the absence of any commercial or financial relationships that could be construed as a potential conflict of interest.

Received: 13 September 2011; accepted: 19 December 2011; published online: 06 January 2012.

Citation: Blanchet EM, Martucci V and Pacak K (2012) Pheochromocytoma and paraganglioma: current functional and future molecular imaging. Front. Oncol. 1:58. doi: 10.3389/fonc.2011.00058

This article was submitted to Frontiers in Cancer Imaging and Diagnosis, a specialty of Frontiers in Oncology. Copyright (c) 2012 Blanchet, Martucci and Pacak. This is an open-access article distributed under the terms of the Creative Commons Attribution Non Commercial License, which permits noncommercial use, distribution, and reproduction in other forums, provided the original authors and source are credited. 